OnLine Journal of Biological Sciences 8 (2): 32-40, 2008

ISSN 1608-4217

(C) 2008 Science Publications

\title{
Microbial Biodiversity Screening for Metal Accumulators from Mineral Ore Rich Site in Andhra Pradesh, India
}

\author{
${ }^{1}$ Aditya Kumar Sarkar, ${ }^{1}$ Susmita Roy, ${ }^{1}$ Ananya Pal, ${ }^{1}$ Sourav Pakrashi, ${ }^{1}$ Prahlad Kumar Mahra, ${ }^{1}$ Sayantee \\ Sahoo, ${ }^{1}$ Aritra Deb, ${ }^{1}$ Madhusmita Mishra, ${ }^{3}$ Sudip Kumar Sen, ${ }^{2}$ Ashoke Ranjan Thakur and \\ ${ }^{1}$ Shaon Ray Chaudhuri \\ ${ }^{1}$ West Bengal University of Technology, BF-142, Sector-1, Salt Lake, Calcutta-700064, India \\ ${ }^{2}$ West Bengal State University (Barasat, North 24 Parganas), Barasat Government College \\ (Annexe Building), 10 KNC Road, Calcutta-700124, India \\ ${ }^{3}$ Department of Biotechnology, Gandhi Institute of Engineering and Technology, Gunupur, \\ Rayagoda, Orissa, India
}

\begin{abstract}
Problem Statement: Since the site selected for screening was a source of magnetite, the objective of this study was to isolate some groups of magnetotactic bacteria and microbes with potential of metal accumulation. Approach: The culture based approach was used for the study. Pure isolates obtained were characterized on the basis of morphology, biochemical tests, physiology as well as at the 16S rDNA based molecular level. They were screened for their metal accumulating ability. Results: Five pure bacterial isolates were obtained by culture dependent method, isolation being done on a modified Magnetospirillum magnetotacticum specific medium (DSMZ-380). These isolates not only exhibited morphological variation as found from Environmnetal Scanning Electron Microscopy (ESEM), but their cell surface also varied greatly in composition which was confirmed from various staining. Similarly another observed fact was that inspite of the same source of isolation, these strains exhibited a varied temperature and $\mathrm{pH}$ tolerance which indicates the diversity in the population. $16 \mathrm{~S}$ rDNA based analysis shows the molecular identification and real time PCR based pathogenecity analysis proved that they lacked $S$. aureus or $P$. aeruginosa like pathogenic gene(s). The isolates were screened for metal accumulating property and all were found to tolerate a wide range of heavy metals and among them certain strains bear high potential of accumulation of metals like copper and chromium. Conclusion: This study reports the isolation and characterization of 5 novel bacterial isolates from the mining area of Andhra Pradesh, India revealing its rich biodiversity. It also points towards the ability of media DSMZ-380 to support growth of metal accumulating non-magnetotactic isolates.
\end{abstract}

Keywords: Magnetospirillium magnetotacticum medium, 16S rDNA, pathogenic gene, heavy metal, energy dispersive $\mathrm{X}$ ray fluroscence

\section{INTRODUCTION}

The diversity of microorganisms make them most abundant on the earth, including the extreme environments. Yet the majority of them are unknown due to the non cultivability of about $96 \%$ of the microbes under the laboratory condition. The unexplored domain of bacteria can have a great potential in the field of agriculture, foresty, food industry, medicine, recycling of precious metal, environmental detoxification and others. In order to understand the exact role of these microbes in environment and how they can be applied to solve environmental problems, they need to be isolated and characterized.

Microorganisms have important roles in formation of earth crust as well as recycling of matter, thus important in understanding the geochemical cycle. Most of the microbes (>90\%) in subsurface or sedimentary environment get attached to particular matters including the dead cells and use them for structural as well as catalytic function ${ }^{[1]}$. One of the area where microbes are quite important is the metalmicrobe interaction ${ }^{[2]}$. The mode of interaction with

Corresponding Author: Shaon Ray Chaudhuri, Department of Biotechnology, West Bengal University of Technology. BF142, Sector- 1, Salt Lake, Calcutta- 700064, India. Tel: 00919831034236. Fax: 00913323341030 
particulate matter like metals may be selective or non selective and also depends upon the external condition. Certain phenomenon exists where the microbial cell surface on getting saturated with metal leads to intracellular uptake of the metal where it gets deposited $^{[3,4]}$.

Microorganism found in metal rich area showed different types of metal-microbe interaction. Most of the interaction occured either on the cell surface of the microbes (bio-sorption) ${ }^{[5]}$ or they were transported into the cellular compartment for further processing. There can be localized accumulation of metals (bioaccumulation) also. The mechanism of interaction with metals depends on the physiological properties of microbes. Certain trace elements are important for the activation of enzymes like nitrogenase $(\mathrm{Mo} / \mathrm{Fe}$ or $\mathrm{V} / \mathrm{Fe}$, or $\mathrm{Fe}$ only), cytochromes ( $\mathrm{Fe}$ ) and cytochrome oxidase $(\mathrm{Fe}, \mathrm{Cu})^{[6,7]}$. All these processes are controlled by genetically determined pathways ${ }^{[8]}$ and sometimes they are fast, nonspecific, and constitutive. The other type of interaction involves the metals/ metalloids as electron acceptors or donors during metabolism.

In the context of bioremediation the microbial interaction with the elements is a means for removal, recovery or detoxification of metal species. This is mainly by the alteration of the behavior of the metal contaminant in the natural or engineered environment. Microorganism also develop a self defense mechanism in their own system against this toxic metal, one of the ways being transport of the metal out of the cell by efflux transport system. The microbial interactions leads to the alteration in the solubility of the metal which cause their mobilization or immobilization and thus helps in removal or detoxification of the contaminant. The alteration can be in terms of oxidation reduction process / involvement of surface charges in interaction with metal / excretion of solvents which helps in solubilization of the metals resulting in their removal or precipitation. One of the potential processes of metal microbe interaction is bioleaching which can be applied to recover valuable metal from a metal rich ore $^{[9]}$. Bioreduction is an important metabolic process that transforms oxide minerals into reduced mineral phases, such as siderite and magnetite and convert dissolved oxidized metal into precipitate. This controls the fate and transport of multivalent metals like Fe(II) and $\mathrm{Mn}(\mathrm{II})$ in groundwater ${ }^{[10]}$.

Different groups of bacteria like Geobacter, Citrobacter, Acinetobacter, Pseudomonads, Sulfate reducing bacteria are reported to have implications in metal transformation. Another similar group are the magnetotactic bacteria which accumulate metal inside the cell, known as Bacterial Magnetic Particles (BMP) which further can be used for different purpose. These uptake the iron such as $\mathrm{Fe}^{3+}$, which moves to cytoplasm, gets converted to ferrous ion $\left(\mathrm{Fe}^{2+}\right)$ and are deposited as magnetite $\left(\mathrm{Fe}_{3} \mathrm{O}_{4}\right)$ or greigite $\left(\mathrm{Fe}_{3} \mathrm{~S}_{4}\right)$. The metal accumulating bacteria have immense application in the field of biotechnology like enzyme immobilization, nanotechnology, immunology and bioremediation.

This study reports the isolation and characterization of a few microbes, isolated from rock dust collected from a magnetite ore rich area. The objective of the work was to study the culture based microbial diversity of metal accumulating bacteria from that location and to evaluate them as potential candidates of biotechnological importance.

\section{MATERIALS AND METHODS}

Site of isolation and cultivation conditions: The source was the rock dust from magnetic ore rich area in Andhra Pradesh, India. This site was selected because it was expected to be rich in microbes which would bear the property of metal tolerance. Since the site was an iron ore rich area, the primary aim was to screen for magnetotactic bacteria, therefore the isolation medium selected was Magnetospirullum magnetotacticum specific DSMZ-380 medium. The medium composition was slightly modified $\left(\mathrm{K}_{2} \mathrm{HPO}_{4} 0.5 \mathrm{gL}^{-1}, \mathrm{NH}_{4} \mathrm{Cl} 0.1\right.$ $\mathrm{gL}^{-1}, \mathrm{CH}_{3} \mathrm{COONa} 1.0 \mathrm{gL}^{-1}$, yeast extract $0.1 \mathrm{gL}^{-1}$ ). Later on, the pure isolates obtained were grown in the enriched medium Luria Bertani broth (1\% tryptone, $0.5 \%$ yeast extract, $0.5 \% \mathrm{NaCl}, 1.5 \%$ agar, $\mathrm{pH} 7-7.5$ ). Since no changes were observed in their morphological features when grown in the enriched medium, hence LB was used for further characterization and maintenance. Unless mentioned otherwise, the cultivation conditions for liquid culture involves overnight incubation at $37^{\circ} \mathrm{C}$ with shaking at $150 \mathrm{rpm}$.

Morphological characterization: The preliminary morphological characteristics were determined by bright field microscopy (Zeiss Axiostar Plus microscope) post simple staining with crystal violet dye. The details of the cell surface were found through general staining procedures like Gram staining, acidfast staining, endospore, capsule and flagellar staining. The cell shape and surface features were explored in more detail by Environmental Scanning Electron Microscopy (FEI QUANTA 200 MARK 2 at 15kV).

Molecular identification: The molecular identification was on the basis of sequence analysis of $16 \mathrm{~S}$ rDNA which occur as a conserved molecule in the bacterial domain. The initial step involved genomic 
DNA isolation by modified alkaline lysis method followed by PCR amplification using universal $16 \mathrm{~S}$ rDNA primers. The detailed procedural steps, the primer specification and PCR conditions were followed as reported by RayChaudhuri et al. ${ }^{[1]}$.The PCR product was cloned into pGEMT- Easy vector and transformed into $E$. coli DH5 hhost by TSS method as reported by Chung et al. ${ }^{[12]}$.Transformed cells containing the desired insert were selected by gel retardation assay and were send for sequencing. The $16 \mathrm{~S}$ rDNA sequences obtained were subjected to BLAST and were submitted to GenBank. The phylogenetic analysis was done by Neighbour Joining method.

Biochemical characterization: Presence of certain extracellular enzymes like protease, lipase, DNase, oxidase, catalase and lecithinase were confirmed following the biochemical characterization techniques as reported by Nandy et al. ${ }^{[13]}$. Specific ready made media (HiMedia laboratory) were used for detection of enzymes like DNase, lipase and lecithinase. Protease was detected on milk medium plates where the enzyme if present degraded the milk protein casein producing a clean zone around the colony. Catalase and oxidase tests are based on the basic property of the enzyme and were done on LB plates containing single colony of pure isolates.

Physiological Charcterization: Since $\mathrm{pH}$ \& temperature are limiting factors governing the microbial growth, determination of the optimum conditions for these parameters are necessary. For temperature profile, the culture $(1 \%)$ was grown in LB broth and was incubated for $12 \mathrm{~h}$ at $20^{\circ} \mathrm{C}, 30^{\circ} \mathrm{C}, 37^{\circ} \mathrm{C}$ and $40^{\circ} \mathrm{C}$ at $150 \mathrm{rpm}$ shaking condition. The Optical Density measured in UV-visible spectrophotometer (Beckman UV Vis spectrophotometer) at $660 \mathrm{nM}$ gave the growth efficiency. To find the $\mathrm{pH}$ range, $\mathrm{LB}$ broths of different $\mathrm{pH}$ were prepared using $\mathrm{NaOH}$ and $\mathrm{HCl}$ for acidic and alkaline range respectively. $1 \%$ inoculum was provided to medium of each $\mathrm{pH}$ range and the bacterial culture was incubated for $12 \mathrm{~h}$ at the optimum temperature found for each isolate. The presence or absence of growth was defined in terms of Optical Density at $660 \mathrm{~nm}$ (UV Vis spectrophotometer).

Growth profile: The overnight grown culture in LB medium acted as the parent source. 1\% inoculation from the parent culture was added to $100 \mathrm{~mL}$ of sterile LB medium and incubated at $37^{\circ} \mathrm{C}$ under $150 \mathrm{rpm}$ shaking. At regular interval of $1 \mathrm{~h}, 3 \mathrm{~mL}$ of culture was aliquoted and the optical density was measured at $660 \mathrm{nM}$ (Beckman UV-Vis spectrophotometer) which represented the extent of growth.

Effect of light/dark on growth: Not only the $\mathrm{pH}$ and temperature but also presence of light play a rate limiting step in bacterial growth. Each isolate was inoculated in LB medium and incubated for the entire growth phase in either darkness or in presence of light (13Watt incandescent lamp from Phillips). In the third set each culture was allowed to grow under alternative cycle of light and darkness. In each set after the entire growth cycle, the extent of growth was measured by checking the Optical Density at 660 nM (Beckman Coulter DV - 530, UV Vis spectrophotometer).

Substrate profile: The isolation medium DSMZ-380 contained sodium acetate as the main carbon source which was replaced by substrates like methanol, ethanol, D.L lactate at the similar concentration. After inoculating $1 \%$ culture, incubation was done in rotary shaker $(150 \mathrm{rpm})$ for overnight at $37^{\circ} \mathrm{C}$. Bacterial growth was measured spectrophotometrically in terms of Optical Density at $660 \mathrm{nM}$.

Esterase assay: Esterase assay was done by spectrophotometric method reported by Lin and $\mathrm{Ko}^{[14]}$ with certain modifications. To $930 \mu$ of Tris $\mathrm{HCl}$ buffer $\mathrm{pH} 9,20 \mu \mathrm{l}$ of $10 \mathrm{mM}$ pNPP was added. $50 \mu \mathrm{l}$ of enzyme solution was added to the reaction mixture, mixed well and incubated at $50^{\circ} \mathrm{C}$ for $20 \mathrm{~min}$. The reaction was stopped by adding $330 \mu$ l of acetone alcohol mixture at ratio of $1: 1$ and absorbance was measured at $410 \mathrm{nM}$. One unit of enzyme activity was expressed as $1 \mu \mathrm{M}$ of PNPP released $/ \mathrm{mL} / \mathrm{min}$.

Antibiotic assay: Susceptibility towards different antibiotics was checked using the antibiotic discs provided by HiMedia Pvt Ltd. The susceptibility was checked on a log phase culture. The antibiotic groups selected, the culture conditions, and the assessment procedure were followed as per Nandy et al. ${ }^{[13]}$

Metal sensitivity test: Each metal was added as supplement in the LB medium and to it $1 \%$ inoculum was given from a log phase culture. The growth conditions were maintained at $37^{\circ} \mathrm{C}$ with constant shaking of $150 \mathrm{rpm}$. The tolerance was determined in terms of growth as visible from the appearance of turbidity. The concentration of metal was incremented in the medium and on the cessation of growth the MIC was determined. Multiple mechanisms could be 
involved in this metal tolerance, one of them being intracellular uptake. Metal accumulation was determined by Energy Dispersive X Ray Fluroscence which gives the quantification of the net metal accumulation as compared to untreated cells. The EDXRF analysis was done for two metals $\mathrm{Cu}$ and $\mathrm{Cr}$ that occur as common contaminants in the environment. Preparation of cells for EDXRF analysis, the procedural details were followed as per Adarsh et al. ${ }^{[15]}$ and Chowdhury et al. ${ }^{[16]}$

Pathogeneicity detection: The isolates were checked for the presence of pathogenic gene of $P$. aeruginosa and $S$. aureus by Taqman Detection Kit of Applied Biosystem. This detection was done by real time PCR to check the amplification of desired gene as per the procedure mentioned in the kit.

\section{RESULTS AND DISCUSSIONS}

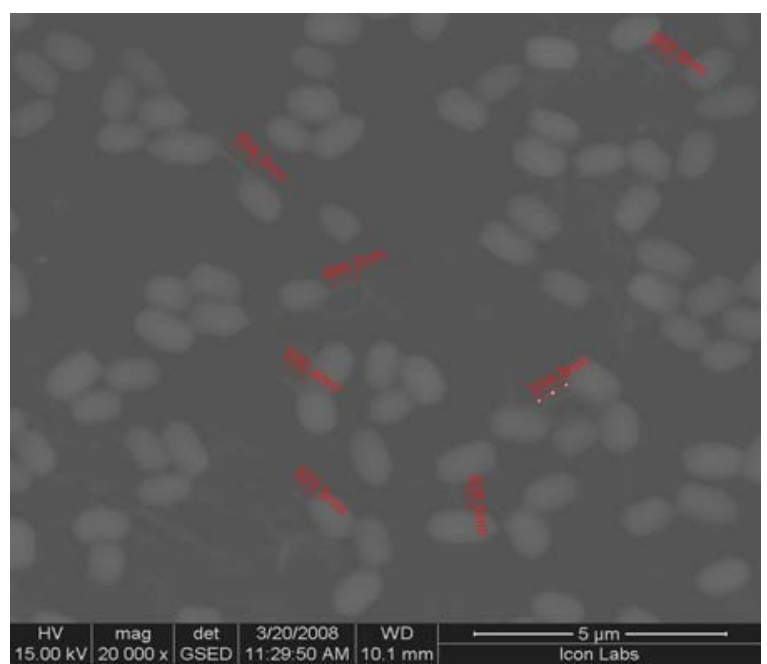

Fig. 1 (i)

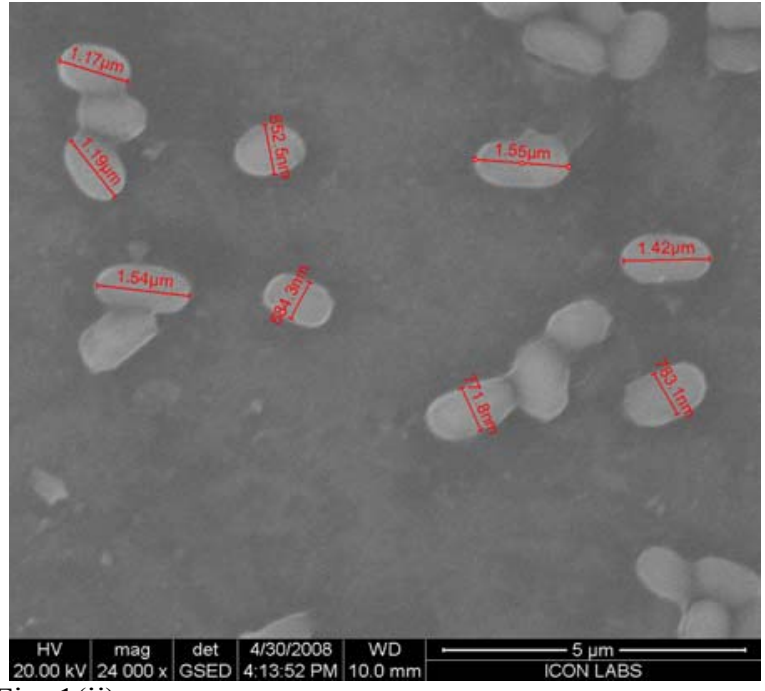

Fig. 1(ii)

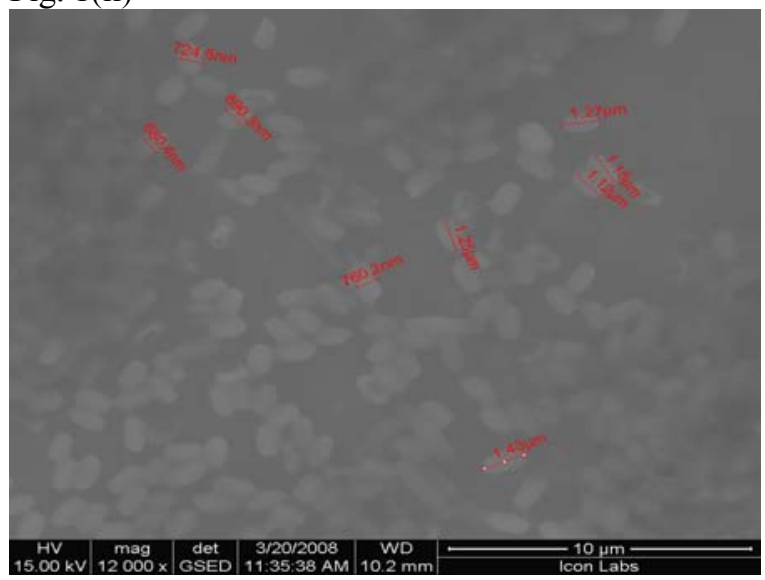

Fig. 1 (iii)

Fig. 1: The scanning electron micrographs representing the structural and dimensional details of the isolates. The smear was prepared on coverslips placed on stubs and were visualized by Environmental Scanning Electron Microscopy technique (FEI QUANTA 200 MARK 2 at $15 \mathrm{kV})$. 1(i) Micrograph showing the bacillus structure of isolate SAP 2 at $20000 \mathrm{X}$ magnification. The presence of pilli like structures were observed between some cells. 1(ii) Micrograph confirming the bacillus structure of isolate SAP3 at 24000X magnification. 1 (iii) Bacillus shaped isolate SAP 4 showing presence of conjugation tubes between some cells (12000X magnification)

Morphological characterization of isolates: At the preliminary step of identification, the isolates exhibited difference in size and shape (Table 1, Fig 1). The 
staining details as put forth in Table 1 indicates that these isolates are of different identity in spite of the same source of isolation. These specific staining procedures revealed the surface details of the isolates, two of them were found to bear flagella while one was found to have a capsule. These structural features also indicated the ability of that particular isolate to use them for survival in extreme environment. Many more typical structural features like presence of pilli like

structure, conjugation tubes (Fig 1 i, iii) were detected with the application of Environmental Scanning Electron Microscopy.

Molecular characterization: The $16 \mathrm{~S}$ rDNA based molecular phylogeny indicated that all the five isolates obtained were novel and belong to different genus. Moreover the partial sequence based analysis can confirm the identity to the genus level. Table 2 shows

isolates as determined from the general staining procedures. The stained smear prepared from a log phase pure culture was visualized under bright field of an Zeiss Axiostar Plus microscope at a 400X magnification.

${ }^{+}+{ }^{*}$ indicates the presence of the specific morphological feature whereas " $-"$ indicates the absence of the property

\begin{tabular}{lllllll}
\hline Isolate & Cell morphology & Gram nature & Acid-fast staining & Capsule staining & Endospore staining & Flagella staining \\
\hline SAP 2 & Bacillus & Gm-ve & - & + & - & - \\
SAP 3 & Bacillus & Gm+ve & - & - & - & + \\
SAP 4 & Cocci & Gm-ve & - & - & - & - \\
SAP 5 & Bacillus & Gm-ve & - & - & - & + \\
SAP 6 & Diplococci & Gm-ve & - & - & - & - \\
\hline
\end{tabular}

Table 2: Table revealing the molecualr identification of the isolates based on partial $16 \mathrm{~S}$ rDNA analysis. The sequence was subjected to BLAST analysis and the identity was deciphered on the basis of the closest neighbour within the existing database showing maximum \% of identity. The partial sequence data confirms the identity upto the genus level and all the isolates being novel their sequences were submitted to Gen Bank and the respective Accession numbers were represented in column 4

\begin{tabular}{llll}
\hline Isolate & Query coverage & $\%$ of identity/ closest neighbour & Gen bank accession No \\
\hline SAP 2 & $73 \%$ & $99 \%$ - Pseudomonas fluorescens. & EU862479 \\
SAP 3 & $71 \%$ & $97 \%$ - Bacillaceae bacterium C11 & EU862480 \\
SAP 4 & $100 \%$ & $100 \%$ - Janibacter anopheles & FJ377715 \\
SAP 5 & $100 \%$ & $100 \%$ - Bacillus licheniformis & FJ377716 \\
SAP 6 & $100 \%$ & $100 \%$ - Acinetobacter baumannii & FJ377717 \\
\hline
\end{tabular}

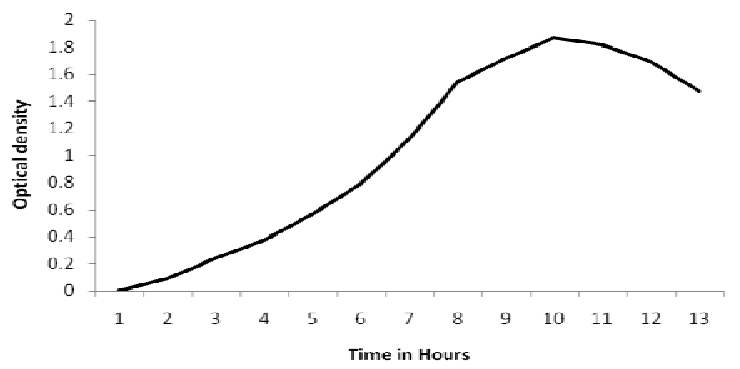

Fig. 2 (i)

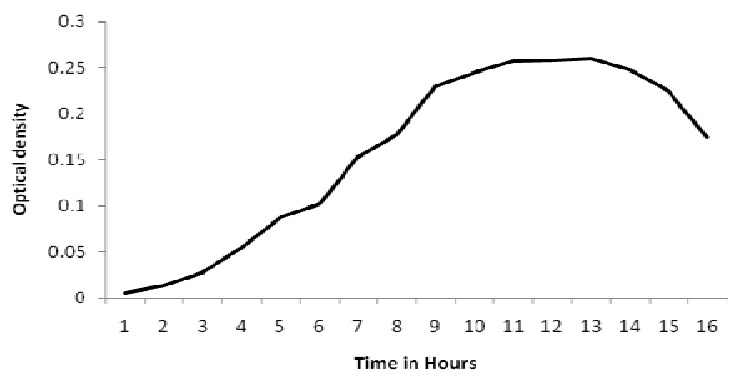

Fig. 2 (ii)

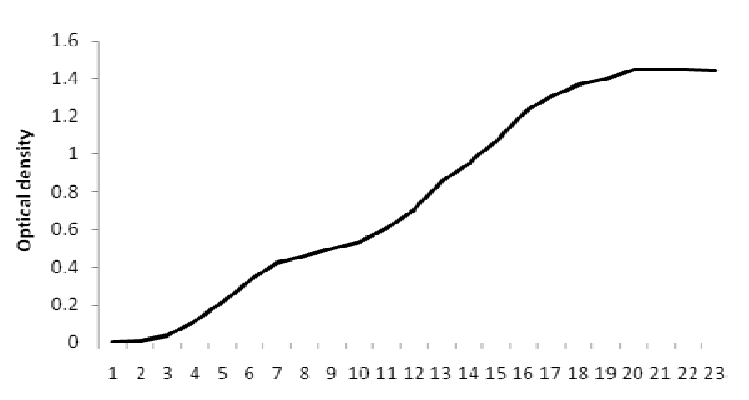

Time in Hours

Fig. 2 (iii)

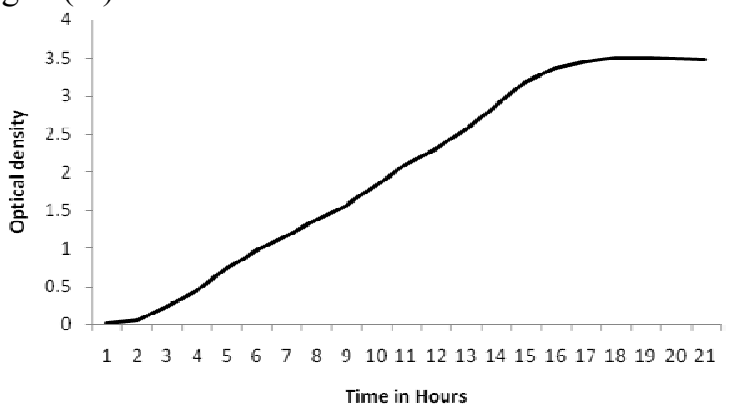

Fig. 2 (iv)

Fig. 2: Figure depicting the growth profile of the four isolates in enriched medium (LB broth); Fig 2 
(i)-Fig 2(iv) represents the growth curve for isolate SAP 2, SAP 3, SAP 5 and SAP 6 respectively. Overnight culture of the pure isolate act as parent culture from where $1 \%$ inoculum was transferred to sterile LB broth and was incubated at $37^{\circ} \mathrm{C}$ under $150 \mathrm{rpm}$ shaking. At regular intervals of 1 hour the growth was checked my measuring the Optical Density at $660 \mathrm{nM}$ (Beckman UV-Vis spectrophotometer). The growth curve for SAP 4 could not be determined due to prolonged log phase of more than $48 \mathrm{~h}$.

the molecular identity based on the BLAST analysis and the GenBank Accession No of the novel clones. The phylogenetic tree based on Neighbour Joining method (Fig 3, 4, 5) also showed the position of the isolates. The most important finding from the molecular analysis was that, though the medium of isolation used

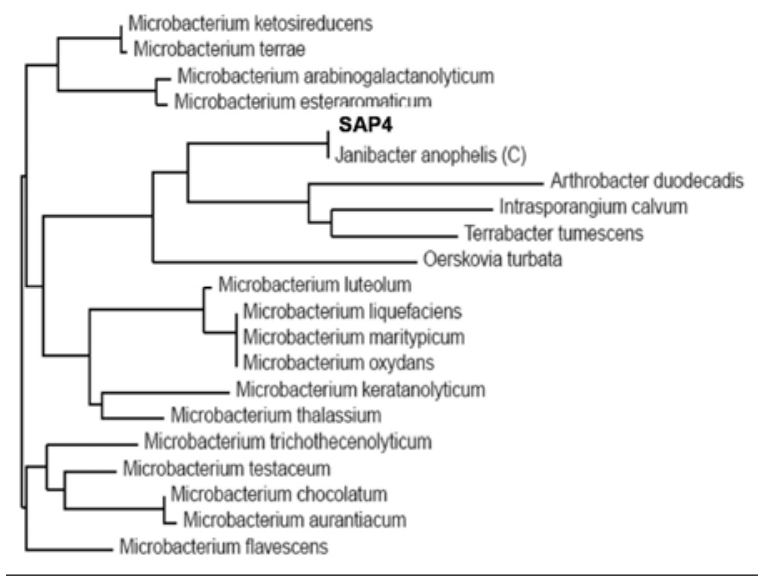

Fig. 3: Phylogenetic tree of isolate SAP 4 constructed using neighbour joining method. The sequence is available at GenBank with accession number FJ377715 and shows $100 \%$ identity with Janibacter anopheles at $100 \%$ query coverage

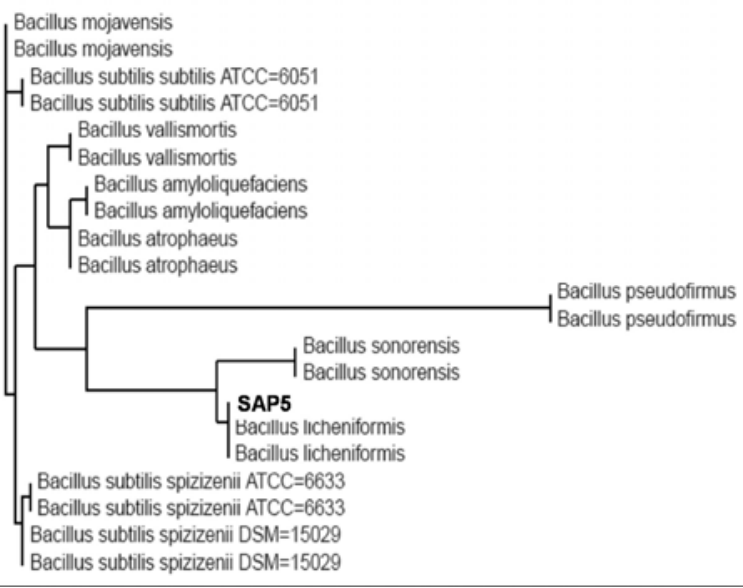

Fig. 4: Phylogenetic tree of isolate SAP 5 constructed using neighbour joining method. The sequence is available at GenBank with accession number FJ377716 and shows $100 \%$ identity with Bacillus licheniformis at $100 \%$ query coverage

was based on that of Magnetospirillium magnetotacticum but none of the isolates were found to belong to this group which indicates that this medium may not act as a specific medium for isolation. Among the five isolates, some were chosen for further biochemical characterization.

Moreover the real time PCR based detection for the presence of pathogenic gene indicated negative result

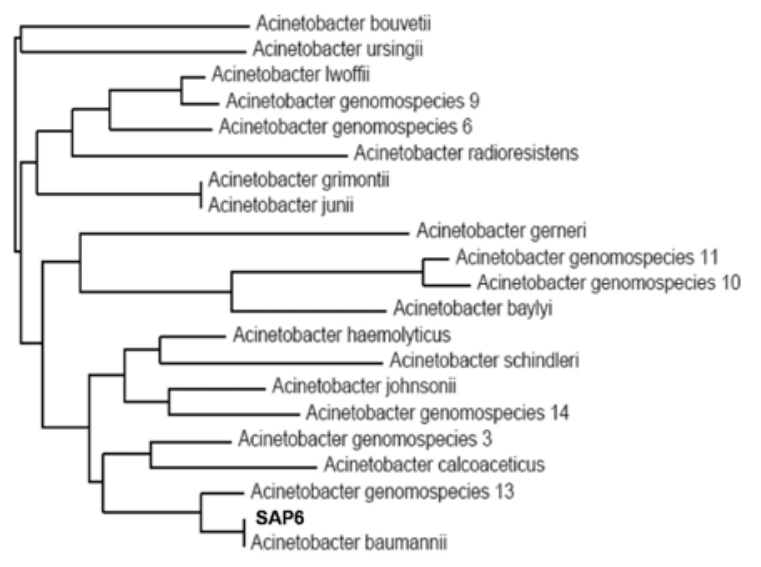

Fig. 5: Phylogenetic tree of isolate SAP 6 constructed using neighbour joining method. The sequence is available at GenBank with accession number FJ377717 and shows $100 \%$ identity with Acinetobacter baumannii at $100 \%$ query coverage 
for both Staphylococcus aureus and Pseudomonas aeruginosa (data not shown).

Biochemical characterization: All the isolates were found to be catalase positive (Table 3 ). The enzyme has been reported to play a role in the defensive mechanism and would be important in the phenomenon of metal microbe interaction. Isolates like SAP 2 and SAP 5 were found to secrete extracellular lipase. The quantitative assay for lipase indicated that SAP 5 secretes about 9 units of enzyme whereas 7 units of lipase were secreted by SAP 2. The enzyme can be of commercial importance when applied in formulation of pharmaceutics and detergents.
Physiological characterization: All the isolates were found to tolerate temperature from $20^{\circ} \mathrm{C}$ to $60^{\circ} \mathrm{C}$ and the optimum temperature for all lies between $37^{\circ} \mathrm{C}$ $40^{\circ} \mathrm{C}$ (Table 3). The $\mathrm{pH}$ profile of the isolates demonstrated an important finding where isolates SAP 5 and SAP 6 were found to tolerate a wider range of $\mathrm{pH}$. The ability to grow at a lower $\mathrm{pH}(\mathrm{pH} 3)$ would be important for the application in area contaminated with acid mine drainage. The light dark profile showed that the growth efficiency was affected differently by light/dark conditions (Table 4). In case of SAP 2, SAP 3 and SAP 4, growth was not much affected by alterations in these conditions where as for SAP 5, growth was accelerated in dark as well as with alternate dark and light phase. In case of SAP 6, light

Table 3: Table showing the biochemical and physiological characteristics of the isolates. Biochemical characterization was determined in terms of presence or absence of the mentioned enzymes. The tests for lipase, DNase, Lecithinase were conducted in specific ready made medium (HiMedia Laboratories), presence of catalase was checked by the observance of effervescence on addition of $\mathrm{H}_{2} \mathrm{O}_{2}$ to isolated single colonies grown on LB medium and oxidase positive property was checked on the basis of the purple coloration of the oxidase disk when brought in contact with the colony. Screening for extracellular protease was checked by the appearance of the clear zone around the colonies on the milk medium.

"+" denotes the enzyme secreting property of the isolate whereas "-" stands for the absence of enzyme secreting property.

\begin{tabular}{|c|c|c|c|c|c|}
\hline \multirow[b]{2}{*}{ Isolate } & \multirow[b]{2}{*}{ Catalase } & \multirow[b]{2}{*}{ Oxidase } & \multicolumn{3}{|c|}{ Biochemical characterization } \\
\hline & & & Lipase & Protease & Lecithinase \\
\hline SAP 2 & + & - & + & - & - \\
\hline SAP 3 & + & - & - & - & - \\
\hline SAP 4 & + & - & - & - & - \\
\hline SAP 5 & + & - & + & - & - \\
\hline SAP 6 & - & + & - & - & - \\
\hline \multicolumn{6}{|c|}{$\begin{array}{l}\text { Table representing the growth efficiency of the isolate under } \\
\text { different conditions of illumination and darkness. The growth } \\
\text { was checked in LB with } 1 \% \text { inoculation, three sets were } \\
\text { subjected to complete darkness, complete light and } \\
\text { alternative light and dark conditions respectively. The growth } \\
\text { efficiency was determined in terms of OD at } 660 \mathrm{nM} \text {. The } \\
\text { average of each is represented in the table }\end{array}$} \\
\hline olates & Light & & Dark & & Light/Dark \\
\hline AP 2 & 0.756 & & 0.801 & & .744 \\
\hline AP 3 & 0.346 & & 0.571 & & .413 \\
\hline AP 4 & 0.896 & & 0.905 & & .800 \\
\hline AP 5 & 0.8233 & & 1.16 & & 1.03 \\
\hline AP 6 & 0.774 & & 0.635 & & 1.3 \\
\hline
\end{tabular}

Table 5: Table presenting the representative data of substrate utilization profile for 4 of the isolates. These substrates were added in order to replace the sodium acetate in the modified DSMZ 380 medium. The growth efficiency was measured under standard cultivation conditions $\left(37^{\circ} \mathrm{C}, 12 \mathrm{~h}, 150 \mathrm{rpm}\right.$ shaking) in terms of optical density at $660 \mathrm{nM}$

\begin{tabular}{lllll}
\hline Substrate & SAP 3 & SAP 4 & SAP 5 & SAP 6 \\
\hline Glucose & 0.010 & 0.045 & 0.168 & 0.138 \\
Lactose & 0.028 & 0.048 & 0.066 & 0.360 \\
Lactate & 0.091 & 0.087 & 0.174 & 0.547 \\
Maltose & 0.012 & 0.037 & 0.375 & 0.309 \\
Sucrose & 0.015 & 0.078 & 0.170 & 0.374
\end{tabular}

Physiological characterization

\begin{tabular}{ll}
$\begin{array}{l}\text { pH range/ } \\
\text { optimum }\end{array}$ & $\begin{array}{l}\text { Temperature range/ } \\
\text { optimum in }{ }^{\circ} \mathrm{C}\end{array}$ \\
\hline NA & NA \\
$6-12 / 8$ & $20-60 / 40$ \\
$6-9 / 8$ & $20-60 / 40$ \\
$3-12 / 10$ & $20-60 / 37$ \\
$5-12 / 6$ & $20-60 / 37$
\end{tabular}

$\begin{array}{lllll}\text { Starch } & 0.037 & 0.074 & 0.374 & 0.451\end{array}$

$\begin{array}{lllll}\text { Sodium acetate } & 0.010 & 0.042 & 0.144 & 0.290\end{array}$

was found to be important for the growth. These results indicate that the light/dark conditions somehow alter the metabolic cycle of the organism. The p-value on performing one way ANOVA was 0.94, 0.005, 0.317, 0.058 and 0.053 for SAP2, SAP3, SAP4, SAP5, SAP6 respectively. This indicates significant variation in case of SAP3, SAP5 and SAP6 at 95\% confidence level.

Different alternative carbon sources were replaced in place of sodium acetate in DSMZ 380 and the utilization efficiency of the isolates were compared. Isolates SAP 5 and SAP 6 were found to utilize these different substrates more efficiently in comparison to others (Table 5). The different substrate utilization indicates the different metabolic pathway of the isolates, for example the pathway of starch utilization would be different from the sugars which would enter the TCA cycle. 
Growth phase: The growth pattern of the isolates was found to vary drastically. Isolate SAP 5 and SAP 6 demonstrated a very short lag phase followed by a long logarithmic phase as compared to SAP 2 and SAP 3 (Fig 2). These details were important for any application where the microbial growth can influence the probable functioning. For example the extent of biodegradation of any contaminant depends on the time length of interaction with the microbe along with the metabolic cycle of the microbe where the contaminant can act as a carbon source.

Antibiotic sensitivity: Table 6 indicates the sensitivity profile of the isolates towards various groups of antibiotics. The resistance and tolerance towards different antibiotics gives an idea of the nature of the correlation with the tolerance towards metals. Since the metal and antibiotic resistance genes are reported to be localized in the same plasmid, the effect of one stress factor can be related to the induction of the other. This explains the co-occurrence of metal and antibiotic resistance together.

Heavy metal tolerance: Sine the objective was to look for metal accumulating bacteria, all the isolates were checked for tolerance for a spectrum of heavy metals and the Minimum Inhibitory Concentration (MIC) gives an idea about the concentration of a metal that a bacterium can tolerate. As depicted in Table 7, all the isolates shows tolerance towards different heavy metals and among them isolates SAP 5 and SAP 6 exhibited maximum tolerance towards $\mathrm{Fe}$ and $\mathrm{Pb}$. The tolerance

isolate and the sensitivity profile provides the

Table 6: Table displaying the representative data of antibiotic sensitivity profile of 4 isolates. The sensitivity was checked in Muller Hinton Agar medium where mid-log phase bacterial culture was spread and on the lawn, different antibiotic disks (supplied by HiMedia Laboratories) were placed and the whole setup was incubated overnight at $37^{\circ} \mathrm{C}$. The zone of inhibition obtained was compared with National Committee for Clinical Laboratory Standard's (NCCLS) chart, and the interpretation of the resistance, sensitivity, or intermediate property was done.

"R" indicates resistance property, "S" denotes sensitivity and "I" indicates the intermediate property of the isolate towards any specific antibiotic

\begin{tabular}{lllllllllllllllllll}
\hline Isolate & $\mathrm{T}$ & $\mathrm{Cq}$ & $\mathrm{C}$ & $\mathrm{Cx}$ & $\mathrm{Pb}$ & $\mathrm{N}$ & $\mathrm{A}$ & $\mathrm{R}$ & $\mathrm{Cf}$ & $\mathrm{Ro}$ & $\mathrm{Do}$ & $\mathrm{Ce}$ & $\mathrm{Ca}$ & $\mathrm{Nx}$ & $\mathrm{G}$ & $\mathrm{Mt}$ & $\mathrm{Tr}$ & $\mathrm{Va}$ \\
\hline SAP 2 & $\mathrm{S}$ & $\mathrm{R}$ & $\mathrm{S}$ & $\mathrm{R}$ & $\mathrm{R}$ & $\mathrm{I}$ & $\mathrm{R}$ & $\mathrm{R}$ & $\mathrm{S}$ & $\mathrm{I}$ & $\mathrm{S}$ & $\mathrm{I}$ & $\mathrm{I}$ & $\mathrm{S}$ & $\mathrm{S}$ & $\mathrm{R}$ & $\mathrm{I}$ & $\mathrm{I}$ \\
SAP 3 & $\mathrm{S}$ & $\mathrm{R}$ & $\mathrm{I}$ & $\mathrm{R}$ & $\mathrm{S}$ & $\mathrm{S}$ & $\mathrm{R}$ & $\mathrm{R}$ & $\mathrm{S}$ & $\mathrm{I}$ & $\mathrm{S}$ & - & $\mathrm{I}$ & $\mathrm{S}$ & $\mathrm{S}$ & $\mathrm{R}$ & $\mathrm{S}$ & $\mathrm{R}$ \\
SAP 5 & $\mathrm{S}$ & $\mathrm{S}$ & $\mathrm{S}$ & $\mathrm{S}$ & $\mathrm{R}$ & $\mathrm{S}$ & $\mathrm{S}$ & $\mathrm{S}$ & $\mathrm{S}$ & - & $\mathrm{S}$ & $\mathrm{S}$ & $\mathrm{R}$ & $\mathrm{S}$ & $\mathrm{S}$ & $\mathrm{R}$ & $\mathrm{S}$ & $\mathrm{S}$ \\
SAP 6 & $\mathrm{S}$ & $\mathrm{R}$ & $\mathrm{S}$ & $\mathrm{R}$ & $\mathrm{S}$ & $\mathrm{R}$ & $\mathrm{R}$ & $\mathrm{I}$ & $\mathrm{S}$ & $\mathrm{R}$ & $\mathrm{S}$ & $\mathrm{I}$ & $\mathrm{I}$ & $\mathrm{S}$ & $\mathrm{S}$ & $\mathrm{R}$ & $\mathrm{S}$ & $\mathrm{R}$ \\
\hline
\end{tabular}

Table 7: The Table represents the Minimum Inhibitory Concentration of metals obtained for different isolates. The determination of MIC was done in LB medium which contains the specific metal salts as supplement. $1 \%$ inoculum was added to the metal containing medium and was incubated at $37^{\circ} \mathrm{C}$ for overnight, the growth was determined by the observance of turbidity. The concentration of metal was increased incrementally till the growth of the isolate was ceased

\begin{tabular}{|c|c|c|c|c|c|c|c|c|}
\hline \multirow[b]{2}{*}{ Isolate } & \multicolumn{7}{|c|}{ Metal salts } & \multirow[b]{2}{*}{$\mathrm{Pb}\left(\mathrm{NO}_{3}\right)$} \\
\hline & $\begin{array}{l}\mathrm{ZnSO}_{4} . \\
7 \mathrm{H}_{2} \mathrm{O}\end{array}$ & $\begin{array}{l}\mathrm{NiCl}_{2} . \\
6 \mathrm{H}_{2} \mathrm{O}\end{array}$ & $\begin{array}{l}\mathrm{CoCl} . \\
6 \mathrm{H}_{2} \mathrm{O}\end{array}$ & $\begin{array}{l}\mathrm{CuSO}_{4} . \\
5 \mathrm{H}_{2} \mathrm{O}\end{array}$ & $\mathrm{Cr}_{2} \mathrm{O}_{3}$ & $\begin{array}{l}\mathrm{Al}\left(\mathrm{NO}_{3}\right)_{3} . \\
9 \mathrm{H} 2 \mathrm{O}\end{array}$ & $\begin{array}{l}\mathrm{FeSO}_{4} . \\
7 \mathrm{H} 2 \mathrm{O}\end{array}$ & \\
\hline & & & & \multicolumn{4}{|c|}{ Concentration in $\mathrm{mM}$} & \\
\hline SAP 2 & 3 & 3 & 1 & 3 & 2 & 3 & 3 & 1 \\
\hline SAP 3 & 3 & 3 & 2 & 2 & 2 & 3 & 3 & 3 \\
\hline SAP 4 & 1 & 1 & 1 & 1 & 1 & 3 & 3 & 2 \\
\hline SAP 5 & 1 & 4 & 1 & 4 & 2 & 6 & 6 & 8 \\
\hline SAP 6 & 10 & 8 & 1 & 5 & 2 & 6 & 11 & 12 \\
\hline
\end{tabular}

Table 8: Table showing the representative data of extent of heavy metal $(\mathrm{Cu}, \mathrm{Cr})$ accumulation within the cell as determined from the EDXRF analysis. Cells were harvested from LB containing a specific metal at the highest concentration (just before MIC level), washed with $0.1(\mathrm{~N}) \mathrm{HCl}$ and PBS and filtered on a membrane filter for analysis by EDXRF system (Jordan Valley, EX3600). The difference in metal concentration in the treated cell and the control cell gave the quantification of metal accumulated inside the cell EDXRF analysis

\begin{tabular}{|c|c|c|c|c|c|c|}
\hline Isolates & $\begin{array}{l}\text { Control cell } \\
\text { without } \mathrm{Cu}\end{array}$ & $\begin{array}{l}\mathrm{Cu} \text { treated cell } \\
\mathrm{Cu} \text { accumulated }\end{array}$ & $\begin{array}{l}\text { Concentration of } \\
\text { without } \mathrm{Cr}\end{array}$ & Control cell & $\mathrm{Cr}$ treated cell & $\begin{array}{l}\text { Concentration of } \\
\mathrm{Cr} \text { accumulated }\end{array}$ \\
\hline & & & \multicolumn{4}{|c|}{ Concentration of metal in ppb } \\
\hline SAP 3 & 6.439 & 8.843 & 2.404 & 3.863 & 5.060 & 1.843 \\
\hline SAP 5 & 5.872 & 5.689 & 0.183 & 3.751 & 38.51 & 34.76 \\
\hline SAP 6 & 5.697 & 5.114 & 0.583 & 3.800 & 38.13 & 34.35 \\
\hline
\end{tabular}


towards Fe was expected since the site of origin being a mineral ore rich site (magnetite ore). The next objective was to check for the efficiency of intracellular accumulation. $\mathrm{Cr}$ and $\mathrm{Cu}$ metals were selected since they are the most common contaminants from industrial exhausts. SAP 5 and SAP 6 showed relatively higher accumulation of $\mathrm{Cu}$ (Table 8) which can be of importance for $\mathrm{Cu}$ recovery as well as detoxification.

\section{CONCLUSION}

Thus this study reveals the presence of 5 novel isolates from the mineral ore rich site in Andhra Pradesh, India. The heavy metal tolerance property of the isolates could be further exploited for means of bioremediation as well as processes like bioleaching for the economical recovery of important metals like Fe and $\mathrm{Cu}$. The detailed characteristics of the isolates in terms of their temperature, $\mathrm{pH}$ tolerance, their growth profile would together facilitate in designing the application process.

\section{ACKNOWLEDGEMENT}

The authors thank Ms Poulomi Nandy for her help during preparation of the manuscript. They thank Department of Biotechnology, Government of India for the funding of M. Tech couse in Biotechnology, West Bengal University of Technology for the funding of Integrated $\mathrm{PhD}$ courses in Microbiology and Molecular Biology as well as Department of Atomic Energy, Government of India for the research funding.

\section{REFERENCES}

1. Ehrlich, H.L., 1997. Microbes and metals. Appl. Microbiol. Biotechnol., 48: 687-692. Doi: 10.1007/s002530051116.

2. Gadd, G.M., 2000. Bioremedial potential of microbial mechanisms of metal mobilization and immobilization. Curr. Opinion Biotechnol., 11: 271-279. Doi: 10.1016/S0958-1669(00)00095-1. http://dx.doi.org/10.1016/S0958-1669(00)00095-1.

3. Macaskie, L.E., A.C.R. Dean, A.K. Cheetham, R.J.B. Jakeman and A.J. Skarnulis, 1987. Cadmium accumulation by a Citrobacter sp.: The chemical nature of the accumulated metal precipitate and its location on the bacterial cells. J. Gen. Microbiol., 133: 539-544. cat.inist.fr $/$ ?aModele $=$ afficheN\&cpsidt $=7427097$.

4. Schultze-Lam, S., D. Fortin, B.S. Davis and T.J. Beveridge, 1996. Mineralization of bacterial surfaces. Chem. Geol., 132:171-181. Doi: 10.1016/S0009-2541(96)00053-8. http://dx.doi.org/10.1016/S0009-2541(96)00053-8.

5. Schiewer, S. and B. Volesky, 2000. Biosorption processes for heavy metal removal. In: Environmental Microbe-Metal Interactions. Washington DC, ASM Press. Lovley D.R. (Ed.). pp: 329-362. ISBN: 1555811957, 9781555811952.

6. Johnson, W.H.O., 1992. Nitrogenase structure: Where to now? Science, 257: 1639-1640. Doi: 10.1126/science. 1529351.

7. Robson, R.L., R.R. Eady, T.H. Richardson, R.W. Miller, M. Hawkins and J.R. Postgate, 1986. The alternative nitrogenase of Azotobacter chroococcum is a vanadium enzyme. Nature, 322: 388-390. Doi: 10.1038/322388a0.

8. Silver, S. and M. Walderhaug, 1992. Gene regulation of plasmid- and chromosomedetermined inorganic ion transport in bacteria. Microbiol. Rev., 56: 195-228. http://mmbr.asm.org/cgi/content/abstract/56/1/195.

9. Olson, G.J., 1994. Microbial oxidation of gold ore and gold bioleaching. FEMS Microbiol. Lett., 119: 1-6. Doi: 10.1111/j.1574-6968.1994.tb06858.

10. Lloyd, J.R., V.A. Sole, V.G.V. Praagh and D.R. Lovley, 2000. Direct and Fe (II)-mediated reduction of technetium by $\mathrm{Fe}(\mathrm{III})$-reducing bacteria. Appl. Environ. Microbiol., 66: 37433749. www.ncbi.nlm.nih.gov/pubmed/10966385.

11. Ray Chaudhuri, S. and A.R. Thakur, 2006. Microbial DNA extraction from sample of varied origin. Curr. Sci., 12: 1697-1700. www.ias.ac.in/currsci/dec252006/1697.pdf.

12. Chung, C.T., S.L. Neimela and R.H. Miller, 1989. One step preparation of competent E. coli transformation and storage of bacterial cells in the same solution. Proc. Natl. Acad. USA., 86: 21722175.

http://www.pubmedcentral.nih.gov/articlerender.fc gi? artid $=286873$.

13. Nandy, P., A.R. Thakur and S. Ray Chaudhuri, 2007. Characterization of bacterial strains isolated through microbial profiling of urine samples. Online J. Biol. Sci., 7: 44-51. 
http://www.scipub.org/fulltext/ojbs/ojbs7144-

51.pdf.

14. Lin, E.S. and H.C. Ko, 2006. Glucose stimulates production of the alkaline-thermostable lipase of the edible Basidiomycete Antrodia cinnamomea. Enzyme Microbial. Technol., 37: 261-265. Doi: 10.1016/J.Enzmictec.2005.03.012.cat.inist.fr/?aMo dele $=$ afficheN\&cpsidt $=16861187$.

15. Adarsh, V.K., M. Mishra, S. Chowdhury, M. Sudarshan, A.R. Thakur and S. Ray Chaudhuri, 2007. Studies on Metal Microbe Interaction of Three Bacterial Isolates From East Calcutta Wetland. OnLine J. Biol. Sci., 7: 80-88. www.scipub.org/fulltext/ojbs/ojbs7280-88.pdf.

16. Chowdhury, S., M. Mishra, V.K. Adarsh, A. Mukherjee, A.R. Thakur and S. Ray Chaudhuri, 2008. Novel metal accumulator and protease secretor microbes from East Calcutta Wetland. Am. J. Biochem. Biotech., 4: 255-264. 